\title{
A Bibliometric Analysis of Industrial Revolution (IR) 4.0 in Construction Engineering Education
}

\author{
Nadia Safura Zabidin ${ }^{1 *}$, Sheila Belayutham ${ }^{1}$, and Che Khairil Izam Che Ibrahim ${ }^{1}$ \\ ${ }^{1}$ Faculty of Civil Engineering, Universiti Teknologi MARA (UiTM), Shah Alam 40450 Selangor, Malaysia
}

\begin{abstract}
Industrial Revolution 4.0 (IR 4.0) is a further development stage of high-tech digitization to enhance communication networks, organization and management as well as production and processes across industries. The rate of changes and its convergence towards IR 4.0 would require new talent, knowledge and skills for current and future generation to retain and generate workforce. As technology in the construction industry is evolving at a fast pace, the current teaching-learning syllabus and pedagogy should change accordingly to accommodate future job requirements. Due to the rawness of this concept in the construction industry, particularly in relation to its education, this study aims to explore the state of the art as well as the state of practice of IR 4.0 and Education 4.0 from the perspectives of construction engineering. Therefore, a systematic review was conducted to analyze the relevant research papers related to IR 4.0 and Education 4.0 within the Scopus database ranging from year 2011 until present. A bibliometric analysis has been outlined following the Preferred Reporting Items for Systematic Review and MetaAnalyses (PRISMA) statement. Findings of this study would provide a thorough understanding on past efforts in advancing the construction engineering education aspect, subsequently highlighting gaps to be filled for future endeavors, particularly in equipping the construction engineering education for IR 4.0.
\end{abstract}

\section{Introduction}

The new paradigm of Industrial Revolution 4.0 (IR 4.0) that would significantly enhance the economic sector and operational environment was introduced back in 2011, at the Hannover Fair by the German Government [1]. The impact of IR 4.0 across different countries and industries vary due to the capital investment of high technology adoptions such as intelligent equipment, advanced information technologies and innovative processes. Despite the steady investment on technologies, the rate of change and its convergence would require new talents, knowledge and skills for the current and future generation in retaining and generating relevant workforces.

Along the same vein, the construction industry is also captivated with the idea of IR 4.0 adoption since this sector acts as one of nation's economic catalyst. The efficiency and good investment return by adopting IR 4.0 elements in the dynamic and complex construction industry sector is the best opportunity to improve the construction processes and productivity, which is currently lacking behind other sectors such as manufacturing and services [2]. The complexity of emerging technology IR 4.0 in the construction industry heavily influences the educational system in supporting the future job requirements.

In order to bridge the gap between construction industry and construction engineering education, collaboration within the two sectors are needed to confront the rapid changes and to obligate with IR 4.0 adaptations by creating an experience-based knowledge education [3]. The higher educational institution is a good platform to introduce Education 4.0 as an on-going development process to strengthen the connection between existing learning courses content with the elements of IR 4.0. The vision for adopting and adapting IR 4.0 in the construction engineering education is to equip the current pedagogy and syllabus content with the new paradigm towards preparing current and future graduates for future job requirements.

Therefore, it is important to develop a construction engineering education principle based on the IR 4.0 concept to meet future challenges in the industry. This study aims to explore the current applications of IR 4.0 and Education 4.0 from the construction engineering perspective. The first objective of this study is to identify the current states of IR 4.0 and Education 4.0 adaptation from the engineering perspective. Secondly, this study further investigates the application of IR 4.0 and Education 4.0 in the field of construction engineering.

A systematic literature review on subjects related to IR 4.0 and Education 4.0 from different journals and conference proceedings within the Scopus database was conducted. The methodology for this study is based on the concept of Preferred Reporting Items for Systematic Review and Meta-Analyses (PRISMA) which consists of four major phases, which are: 1) identification; 2) screening; 3) eligibility; and 4) inclusion to critically investigate the subject matter [4].

\footnotetext{
* Corresponding author: nadiasafura@gmail.com
} 


\section{Literature Review}

IR 4.0 is the conversion of computer and automation into cyber-physical system, significant to a combination between real world and virtual world in operations based on information and communication technology [5].The concept of IR 4.0 will enhance operations into fully integrated, automated and optimized process flows for a greater efficiency and change in traditional work ethics among people, machine and system [6]. The main features of IR 4.0 are system integration, industrial internet, cybersecurity, cloud computing, big data analysis, artificial intelligence, augmented reality, simulation, additive manufacturing, advanced robotics and advanced material[5,6].

Generally, the application of IR 4.0 in the construction industry involves technologies, communication and collaboration to enhance the current methodology. A wide range of technologies and concepts to automate the construction processes and to create a new construction environment have been observed through the adoption of smart factories, simulation and modelling, digitization and virtualization as key enablers for project management applications and digital document management platforms for information access [7]. Hence, the radical change in the construction industry would subsequently transform the construction education, especially in the engineering discipline so that the current education system educates future graduates in accordance to the current technological trend based on IR 4.0, through the establishment of Education 4.0. [8].

Global transformation of IR 4.0 is basically an enormous conversion for the education needs in the field of engineering to achieve the goal of integrating industrial skills, knowledge and experience in the pedagogy [9]. The needs of IR 4.0 in education is a platform to introduce future graduates to IR 4.0 through real working environment exposures towards fulfilling future job requirements and to overcome industrial challenges worldwide. It is vital to address the current on-going developments of various technologies in strengthening the connection between existing learning course content and related disciplines as a key development in education institutions, towards embracing Education 4.0. [10].

\section{Methodology}

A systematic literature review (SLR) is an essential method to define a clear and relevant investigation of previous research based on research topics, area or phenomenon of interest. This method is defined as a form of secondary study that uses a distinct methodology to pinpoint, appraise and interpret all reachable evidence in relation to a specific research queries in an unbiased and repeatable ways [11]. The characteristics of SLR is to identify relevant paper selections based on question, appraise the paper critically to assess the research strategy, analyse the data by including and excluding information through certain principles and to report the analysis based on the results from previous research papers [12].

The SLR conducted in this study is guided by the main question: What is the current applications of IR 4.0 and Education 4.0 in the construction engineering discipline? More specifically, other guiding subquestions are listed as follows:

I. Q1: What is the current state of IR 4.0 and Education 4.0 from the engineering perspective?

II. Q2: How has IR 4.0 and Education 4.0 been implemented in the field of construction?

\subsection{Preferred Reporting Items for Systematic Review and Meta-Analysis (PRISMA)}

The PRISMA statement is used to provide a comprehensive contextual understanding of previous studies to be published as a transparent and critically assessed report [4]. PRISMA comprises of four-phases in a flow diagram, which are: 1) identification; 2) screening; 3) eligibility; and 4) inclusion [13]. Figure 1 presents the results of PRISMA analysis.

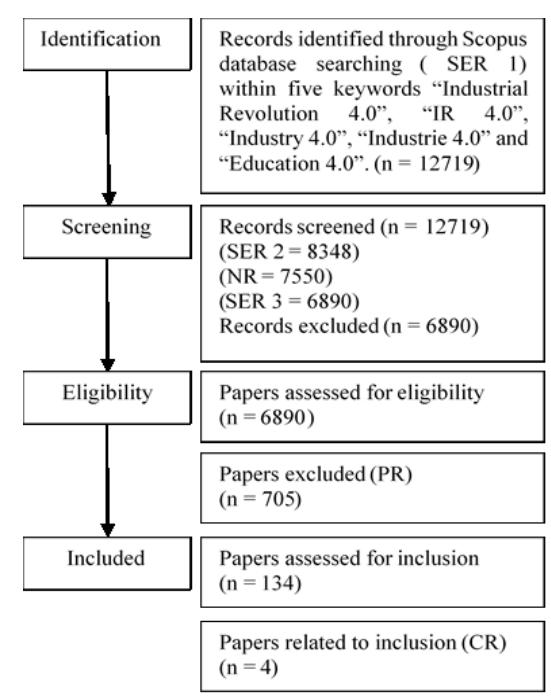

Fig. 1. The systematic literature review flowchart.

The efficiency of a SLR flow diagram and its results is closely related to the Inclusion/Exclusion (I/E) criteria of the SLR methodology, as given in Table 1. In General, the first stage of identification consists of five major keywords which are "Industrial Revolution 4.0", "IR 4.0", "Industry 4.0", "Industrie 4.0", and "Education 4.0". A total of 12719 papers were from the search engine Scopus database (SER 1 in Table 1). In the second stage, a total of 8348 papers were published after the Industry Industrial 4.0 have been officially introduced in 2011 at the Hanover Fair by the German Government [1] (SER 2 in Table 1). Then, 7550 papers selected were published in journals, conference 
proceedings or books and finally, a total of 6890 papers were limited to papers written in English language only (SER 3 and NR in Table 1). The third stage is to ensure all eligible papers related to the four keywords followed earlier are studied in detail using the "engineering" and "construction" topics keywords (PR in Table 1). A total of papers found at this eligibility stage were 705. Finally, only 4 relevant papers closely related to "education" in construction engineering were found within the four keywords selected (CR in Table 1).

\subsection{Exclusion and Inclusion Review Principle}

The assessment criteria for this study is shown in Table 1, which comprises the principles of exclusion and inclusion to convey accurate research findings

Table 1. Inclusion/ Exclusion Criteria

\begin{tabular}{|c|c|c|c|}
\hline $\mathrm{I} / \mathrm{E}$ & Criteria & \multicolumn{2}{|c|}{ Criteria Explanation } \\
\hline \multirow{6}{*}{ 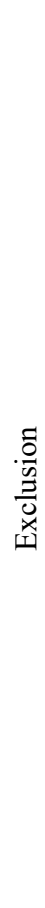 } & \multirow{3}{*}{$\begin{array}{l}\text { Search } \\
\text { Engine } \\
\text { Reason } \\
\text { (SER) }\end{array}$} & $\begin{array}{l}\text { SER } \\
1:\end{array}$ & $\begin{array}{l}\text { The search engine used was } \\
\text { Scopus }\end{array}$ \\
\hline & & $\begin{array}{l}\text { SER } \\
2:\end{array}$ & $\begin{array}{l}\text { All searches were limited to } \\
\text { works published from } 2011 \\
\text { until the current year } \\
\text { because the IR } 4.0 \text { have } \\
\text { been officially introduced in } \\
2011 \text { at the Hanover Fair by } \\
\text { the German Government }\end{array}$ \\
\hline & & $\begin{array}{l}\text { SER } \\
\text { 3: }\end{array}$ & $\begin{array}{l}\text { Papers with relevant title, } \\
\text { abstract and keywords in } \\
\text { English only }\end{array}$ \\
\hline & $\begin{array}{l}\text { Without } \\
\text { Full-text } \\
\text { (WF) }\end{array}$ & & $\begin{array}{l}\text { Papers without full texts } \\
\text { were assessed }\end{array}$ \\
\hline & $\begin{array}{l}\text { Non } \\
\text { Related } \\
(\mathrm{NR})\end{array}$ & & $\begin{array}{l}\text { Excluded articles published } \\
\text { in letter, editorial, note, } \\
\text { short survey, business } \\
\text { article or press and erratum }\end{array}$ \\
\hline & $\begin{array}{l}\text { Loosely } \\
\text { Related } \\
\text { (LR) }\end{array}$ & & $\begin{array}{l}\text { The content is irrelevant } \\
\text { with keywords searched } \\
\text { "Industrial Revolution 4.0", } \\
\text { "Industry 4.0", "IR 4.0", } \\
\text { "Industrie 4.0" and } \\
\text { "Education 4.0" }\end{array}$ \\
\hline & $\begin{array}{l}\text { Partially } \\
\text { Related } \\
(\mathrm{PR})\end{array}$ & & $\begin{array}{l}\text { Search mentioning } \\
\text { construction engineering } \\
\text { based on the four keywords }\end{array}$ \\
\hline 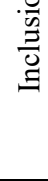 & $\begin{array}{l}\text { Closely } \\
\text { Related } \\
\text { (CR) }\end{array}$ & & $\begin{array}{l}\text { Focus on papers containing } \\
\text { the descriptions of } \\
\text { Education in Construction } \\
\text { Engineering within the four } \\
\text { keywords }\end{array}$ \\
\hline
\end{tabular}

\section{Results and Discussion}

Within the 705 papers collected containing the "education" keyword, the top five subject areas related to IR 4.0 are medicine $(39 \%)$, engineering $(22 \%)$, social science $(17 \%)$, computer science $(17 \%)$ and decision science (5\%). Figure 2 showed the results of top five documents by subject area.

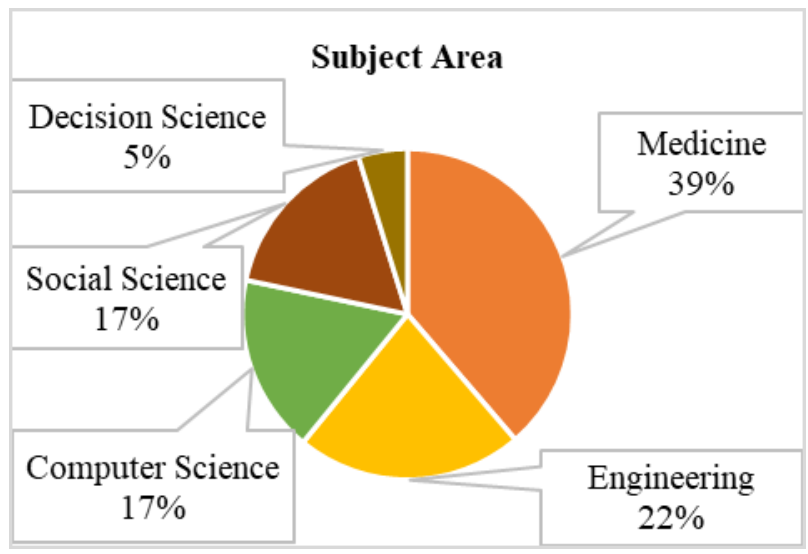

Fig. 2. Percentage of top five subject area

Narrowed down into the $22 \%$ of the findings in the engineering aspect, 134 documents were found in the database. Based on Figure 3, six categories of subjects were found in this engineering research which are science and technology (57\%), manufacturing (34\%), electrical (4\%), civil engineering (3\%), mechanical (1\%) and Chemical (1\%).

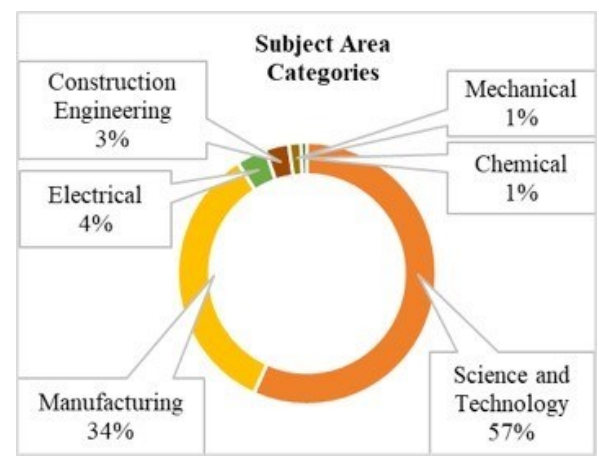

Fig. 3. Percentage of subject area categories

Finally, only four papers were observed in relation to this SLR's objective, which is to investigate the current application of IR 4.0 and Education 4.0 in construction engineering disciplines. Details of the four papers are tabulated in Table 2.

Table 2. Papers related to this research

\begin{tabular}{|c|c|c|c|}
\hline Title & Author & Year & Country \\
\hline $\begin{array}{l}\text { Augmented } \\
\text { Reality gaming } \\
\text { in Sustainable } \\
\text { Design } \\
\text { Education }\end{array}$ & $\begin{array}{l}\text { Steven K. } \\
\text { Ayer, John } \\
\text { I. Messner } \\
\text { and Chimay } \\
\text { J. Anumba }\end{array}$ & 2016 & $\begin{array}{l}\text { United } \\
\text { States }\end{array}$ \\
\hline $\begin{array}{l}\text { HOME I/O and } \\
\text { FACTORY I/O: } \\
\text { A virtual house } \\
\text { and a virtual } \\
\text { plant for control } \\
\text { education }\end{array}$ & $\begin{array}{l}\text { B. Riera and } \\
\text { B. Vigario }\end{array}$ & 2017 & France \\
\hline $\begin{array}{l}\text { Freshman } \\
\text { project launches }\end{array}$ & $\begin{array}{l}\text { Chun-Wen } \\
\text { Teng }\end{array}$ & 2017 & Taiwan \\
\hline
\end{tabular}




\begin{tabular}{|l|l|l|l|}
\hline $\begin{array}{l}\text { the cultivation of } \\
\text { future } \\
\text { engineering } \\
\text { talent }\end{array}$ & & & \\
\hline $\begin{array}{l}\text { Incorporating } \\
\text { Pre-recorded } \\
\text { Environmental } \\
\text { Lifecycle } \\
\text { Assessment } \\
\text { Modules in a }\end{array}$ & $\begin{array}{l}\text { Haselbach Quinn } \\
\text { anditt }\end{array}$ & & \\
Classroom & & & \\
Setting & & & \\
\hline
\end{tabular}

The first paper is titled "Augmented reality gaming in sustainable design education" by Ayer et al [14], who stated that it is important for students to be able to generate, envision and evaluate the performance of alternative building design and construction options that will effect buildings' performance. This research has introduced 108 students from architectural engineering, architectural and civil engineering discipline to the use of augmented reality-based educational game called ecoCampus. In order to explore the pedagogical value of this technology, two groups have been developed, where one group was assigned to use the ecoCampus tools, while the other group used paper-based design activities. The findings suggest that, the students who used ecoCampus were able to overcome the inclination towards design fixation, further enabling them to use the application to assess design and also to generate additional concepts, as compared to the students who have used the paper-based format.

The second study is entitled "HOME I/O and FACTORY I/O: A virtual house and a virtual plant for control education" by Riera and Vigarioe [15], who introduced serious games for control education named HOME I/O and FACTORY I/O software. This indicator was used to raise the awareness on the use of new technologies to advance programming and analysis skills between information technology and operating technology. The purpose of the simulation and modelling was to evaluate the system such as environmental parameters, power consumption and many more before developing the physical commissioning processes.

The third paper is by Teng [16], entitled "Freshman project launches the cultivation of future engineering talent" that discusses about the conceive, design, implement and operate (CDIO) framework. According to this research, CDIO framework has emphasized on integrated curriculum so that students can master the basic principles and professional knowledge as early as in the first-year of university. The participants of the freshman projects have approved this educational framework. process as it helps them to improve their understanding on the courses and the importance of collaborations between other disciplines in universities.

Finally, is a research entitled "Incorporating prerecorded environmental Lifecycle Assessment (LCA) modules in a classroom setting" by Haselbach and Langfitt [17], where its objective was to examine the effectiveness of using short pre-recorded software modules on LCA class or a smart classroom. A small group of 15 students at Washington State University
(WSU) have participated in this module, where surveys were later conducted to assess their understanding on the modules' outcomes. The results of this research were positive because the new educational framework modules and smart classroom were appropriate and attractive for students' aid in the rapid fusion of sustainability topics in engineering programs.

The findings of this paper show that there are four previous studies that have discussed specifically on the application of IR 4.0 and Education 4.0 in the construction engineering discipline. The main components include augmented reality, simulation and modelling, smart classroom and educational framework. According to the IR 4.0 concept, gamification lays in the augmented reality components by providing a real-time information to improve decision making and to enhance work procedures. Meanwhile, simulation is a component that leverages the real-time data to mirror the physical world in virtual model such as 2D and 3D software. Gamification and software in construction engineering disciplines plays an important role in order to adapt IR 4.0 in the education system. This application can help to improve students' awareness and enhance their understanding, thus demonstrating the importance of IR 4.0. Even though the science and technology as well as the manufacturing sector dominates the IR 4.0 papers in the Scopus database, the construction engineering promises a greater development towards approaching IR 4.0 in order to meet the future job requirements.

\section{Conclusion}

Industrial Revolution 4.0 is the latest intelligence spotlight to be adopted and adapted in all education disciplines especially in construction engineering at higher education institution, in order to satisfy future job requirements and to compete in real working environment for human capital development. The essence of IR 4.0 in education could act as a benchmark and guideline to improve the current pedagogy and finally, contributes to a new technology infused approach in improving education for the construction industry discipline.

The transformation of education strategies and approaches in accordance to the latest trend to meet the industry's competence development is a platform to improve students' skills and knowledge. IR 4.0 components and Education 4.0 application contributes to ease the path towards new construction engineering syllabus, in order to ride along the wave of industrial revolution 4.0 and also to strengthen the education processes, subsequently towards preparing future People 4.0 for the construction industry.

Based on the objectives of this study, the findings have discovered new applications to integrate IR 4.0 in the construction engineering discipline, which are augmented reality and simulations. However, there were only four papers found objectively related to IR 4.0 and Education 4.0 in the field of construction engineering education. The only countries contributed to this finding were United States, Taiwan and France. Due to the very 
little study found on this very important subject matter, the higher education and decision makers should explore further the pedagogical value and means of adapting IR 4.0 in the current construction engineering syllabus to enhance student's skill and knowledge to facilitate future job requirements.

This study has been conducted methodologically through the processes of PRISMA but is constrained to certain limitations due to the choice of keywords ("Industrial Revolution 4.0"; "IR 4.0"; "Industry 4.0"; "Industrie 4.0"); "Education 4.0") used. However, only a small number of findings have been retrieved based on the five main keywords used, which might not represent a complete overview on the construction engineering perspective. These findings disregard detailed application/ components such as big data, Internet of Things, simulation, industrial internet and many more.

Future studies could be conducted to widen the findings in regard to IR 4.0 and Education 4.0 in construction engineering education by expanding the keywords used, as well as the use of other databases such as Web of Science (WoS), Science Direct and ASCE for a comprehensive research finding. Nonetheless, findings of this study have demonstrated the huge gap in the study related to IR 4.0 construction engineering education, subsequently exemplifying future research opportunities in the subject area.

This research was supported by the Faculty of Civil Engineering and Bestari Perdana grant, Universiti Teknologi MARA [Grant No: 600-IRMI/PERDANA 5/3 BESTARI (065/2018)].

\section{References}

1. M. Baygin, H. Yetis, M. Karakose, and E. Akin, 15th Int. Conf. Inf. Technol. Based High. Educ. Train., 1, (2016).

2. P. E. A. Holt and N. Kearney, 122nd ASSEE Annu. Conf. Expo., (2015).

3. F. Baena, A. Guarin, J. Mora, J. Sauza, and S. Retat,. 9, 73, (2017).

4. D. Moher Liberati A, Tetzlaff J., PLoS Med., 6, (2009).
5. R. Geissbauer, S. Schrauf, V. Koch, and S. Kuge, PricewaterhouseCoopers, 52, (2014).

6. S. Vaidya, P. Ambad, and S. Bhosle, Procedia Manuf., 20, 233, (2018).

7. T. D. Oesterreich and F. Teuteberg, Comput. Ind., 83, 121, (2016).

8. S. M. Sackey and A. Bester, South African J. Ind. Eng., 27,101, (2016).

9. L.-W. Ting and Giffen-Cheng, Proc. Ieee Int. Conf. Adv. Mater. Sci. Eng., 448, (2016).

10. P. Eichinger, B. Höfig, and C. Richter, 2017 Int. Conf. Res. Educ. Mechatronics, 1, (2017).

11. B. Kitchenham and S. Charters, Engineering, 45, 1051, (2007).

12. Y. Zurynski Aust. Paediatr. Survaillance Unit, 1 (2014).

13. A. Liberati, Altman DG, Tetzlaff J., BMJ, 339, (2009)

14. S. K. Ayer, J. I. Messner and C. J. Anumba., J. Archit. Eng., 22, 1, (2016).

15. B. Riera and B. Vigário, IFAC-PapersOnLine, 50, 9144, (2017).

16. C. W. Teng, IEEE Int. Conf. Appl. Syst. Innov. Appl. Syst. Innov. Mod. Technol. ICASI 2017, 292, (2017).

17. L. Haselbach and Q. Langfitt, J. Prof. Issues Eng. Educ. Pract., 143, D5016001, (2017). 